\title{
Experimental Study of the Durability of Cutting Tips Prepared via Powder and Casting Me- tallurgy
}

\author{
Peter Monka ${ }^{1}$, Katarina Monkova ${ }^{1,2}$, Libuše Sýkorová $^{2}$, Martin Novak $^{3}$ \\ ${ }^{1}$ TU Kosice, Faculty of Manufacturing Technologies with the seat in Presov, Sturova 31, 08001 Presov, Slovakia, E- \\ mail: katarina.monkova@tuke.sk, peter.pavol.monka@tuke.sk \\ ${ }^{2}$ UTB Tomas Bata University in Zlin, Faculty of Technology, Vavreckova 275, 76001 Zlin, E-mail: monkova@utb.cz, \\ sykorova@utb.cz \\ ${ }^{3}$ Faculty of Mechanical Engineering, J. E. Purkyně University in Ústí nad Labem, Pasteurova 3334/7, 400 96 Ústí nad \\ Labem, Czech Republic, E-mail: martin.novak1@ujep.cz
}

\begin{abstract}
Machining has long been the most used technology in manufacturing processes. On the other hand, new materials are being developed or new ways of preparing them are being developed. One of such materials is High Speed Steel (HSS). The article deals with experimental study of a cutting tool durability prepared via powder and casting metallurgy. Durability of cutting tips produced from HSS Vanadis 30 (SN 41 9830) were tested during the shortterm radial tests. Three modifications of the HSS steel were studied, while two types of them were prepared via powder metallurgy and the third one was made via casting metallurgy. The measured values were statistically processed and submitted to the remoteness testing according to Grubbs. The results have shown that the most appropriate material for production of cutting tips, ranked based on three studied steels from the durability point of view, appears Vanadis 30 produced via powder metallurgy alloyed by component $\mathrm{Nb}$.
\end{abstract}

Keywords: durability, cutting tip, high speed steel, metallurgy, lathe-turning test

\section{Introduction}

Efficiency of a tool depends on the operating conditions of the cutter edge. To enable the rational use of the tool, it is necessary to identify phenomena in the contact area, the most important factors such as normal and shear stress as well as thermal phenomena linked with the parameters of cutting, material and geometry. [1] Regardless of the differences in the values and trends of the normal and shear stresses at the contact interfaces, minimum tool wear occurs and apparent friction coefficient reaches its lowest value at the optimum cutting speed [2,3]. Wear of a cutting tool is a change in its geometry, material loss and loss of cutting properties, that result from the operation of the tool. Wear of a cutting tool is caused by tribological processes, which take place between the cutting tool and processed material. This is compounded by the impact of chemical and thermal interactions. [4-6]. The tool durability depends primarily on wear resistance of tool material [7]. This requires tool materials assuring a set of such important properties as hardness, strength, temper - ability and thermal conductivity. The selection of material for a suitable tool is dependent on the method of its wear or destruction. This selection is given by the tool material and work conditions, which affect the method of the tool wear. [8]

To be objectively considered the durability of the tool made from high-speed steels prepared via powder metallurgy, it was necessary to compare them with the equivalent steel produced via casting metallurgy at the same conditions. It was the goal of the experiments described below.

\section{Material of cutting tips}

The high-speed steels (HSS) represent a special category of highly alloyed tool steels, with alloying element content up to $30 \%$ and combining properties such as high hot hardness and higher wear resistance. These properties are possible to be attained due to a special microstructure, composed of a matrix around $65 \mathrm{HRC}$ and hard primary carbides, rich in molybdenum, tungsten and vanadium. From a microstructure point view, high speed steels can be described as metallic matrix composite formed by a ferrous matrix with a dispersion as well as the properties of the material depend on the chemical composition and manufacturing processes. Owing to its high hot hardness and wear resistance, HSS have been widely used to manufacture cutting tools and wear parts.

High-speed steels can be obtained by three distinct methods, casting, powder metallurgy and spray forming. [9]

Using casting metallurgy as conventional production process of high speed steels, the high carbon and alloy contents and slow cooling of ingot casting result in a coarse as-cast microstructure, leading to very low toughness and ductility due to Non-homogeneous, coarse-grained texture with uneven distribution of highly coarse carbides. During the consequent hot working step, the coarse primary carbides are broken finer to some extent, but are distributed in strings parallel to the deformation directions, which is responsible for anisotropic properties of the material and may cause distortion after treating and decrease toughness in the transverse direction. Very high reductions (up to $94 \%$ ) are necessary to be achieved fine and uniform distribution of carbides. The utilization of the material in this case is only $50 \%$. [10]

The casting route usually leads to a microstructure with segregation and poor carbide size distribution. This may affect the material performance, but can be minimised by post thermal mechanical treatments, at a cost penalty. 
Despite of the continuous improvement in all stages of high speed steels production by conventional metallurgical procedures, as a result of segregation taking place during solidification and differences in the solidification rate of metal in the volume of ingots (these phenomena result from the physical nature of the process and cannot be completely suppressed), carbides in these steels are in irregular form and different size. They are often large and form chains and clusters which remain in the material even after partial disintegration by intense forming. This results in the formation of different defects in the material during hardening, reduces toughness and cutting properties and impairs the grind ability. [11-13]

Development of the tools production and, in particular, high speed steels by powder metallurgy procedures has been necessitated by the requirement to eliminate the disadvantages of conventional metallurgy. The metal powder is compacted by placing in a closed metal cavity (the die) under pressure. This compacted material is placed in an oven and sintered in a controlled atmosphere at high temperatures and the metal powders coalesce and form a solid. A second pressing operation, repressing, can be done prior to sintering to improve the compaction and the material properties. Advantages of the application of high-speed steels, which are produced via powder metallurgy method compared to the casting metallurgy are in better material utilization and in better properties. Higher chemical and structural homogeneity, finer primary carbides, smaller grain sizes and absence of carbide stringers are some characteristics attained. As result of

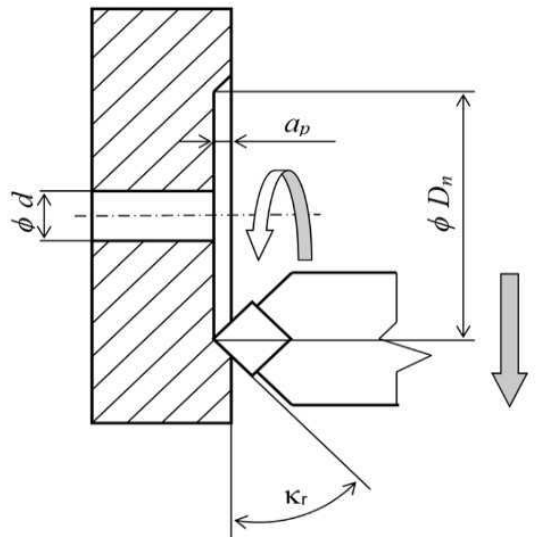

such microstructure, they have higher toughness, higher hardness after heat treating and are more isotropic structure. Another advantage of PM is the possibility of producing any combination of alloy composition; for conventionally produced HSS, however, the chemical composition arrange is limited by hot workability. [14,15]

\section{Conditions of experiments}

The test at radial turning appears as one of the effective methods where the cutting life of some materials produced on the basis of high-speed steel through powder or casting metallurgy are compared. This experiment is a short-term test with acceptable accuracy and it is usually used to detect the machinability of machined material. The test is based on the fact that the disk is machined from the hole surface, designed in the middle of the disc, to its circumference. It means that the cutting speed gradually increases and at a certain diameter Dn the cutting speed reaches a maximum value vn, at which the cutting ability of the tool material is complete lost. [16]

The important parameter for the evaluation of Cutting life - Speed dependence is the radius, at which the tool wear occurred. These obtained values are used for statistical processing of constants and exponents of Taylor's equation in implicit form. [17] A constant depth of cut ap and a constant feed per revolution are kept during the whole experiment. Schematic principle of the test is shown in Figure 1.

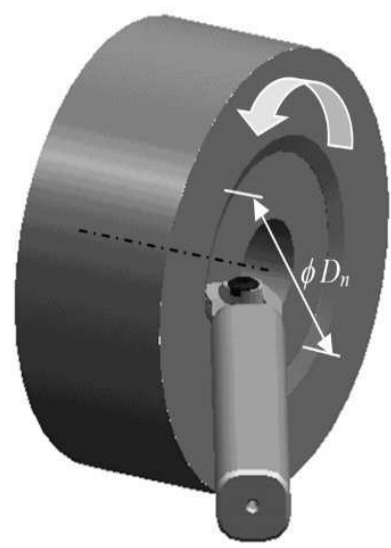

Fig. 1 Principle of the short-term test of durability by radial turning

The basic requirements for the methodology of cutting life testing by radial turning are:

- all tools used in the experiments have to have the same geometry of the cutting wedge

- in each of experiments is used new cutting wedge (tool),

- $\quad$ it is necessary to keep a constant cutting depth $a_{p}$ and feed per revolution $f$,

- $\quad$ it is necessary to specify the number of tools so to be reached a required level of statistical significance.
The main advantages of this method are as follows: high efficiency, saving time and material, satisfactory accuracy and unpretentiousness for measurement equipment.

Steel C45 (DIN 17200 - 84; 12050.1 according to STN standard) was used as machined material. A workpiece is shown in Fig. 2.

For the tests of tool cutting life by radial turning was used the lathe SV 18 RA that ensured

- adequate rigidity of a technological set,

- stability of operating speed frequency,

- $\quad$ sufficient power output,

- sufficient rigidity and clamping range of jaw,

- $\quad$ sufficient maximal diameter of the workpiece. 


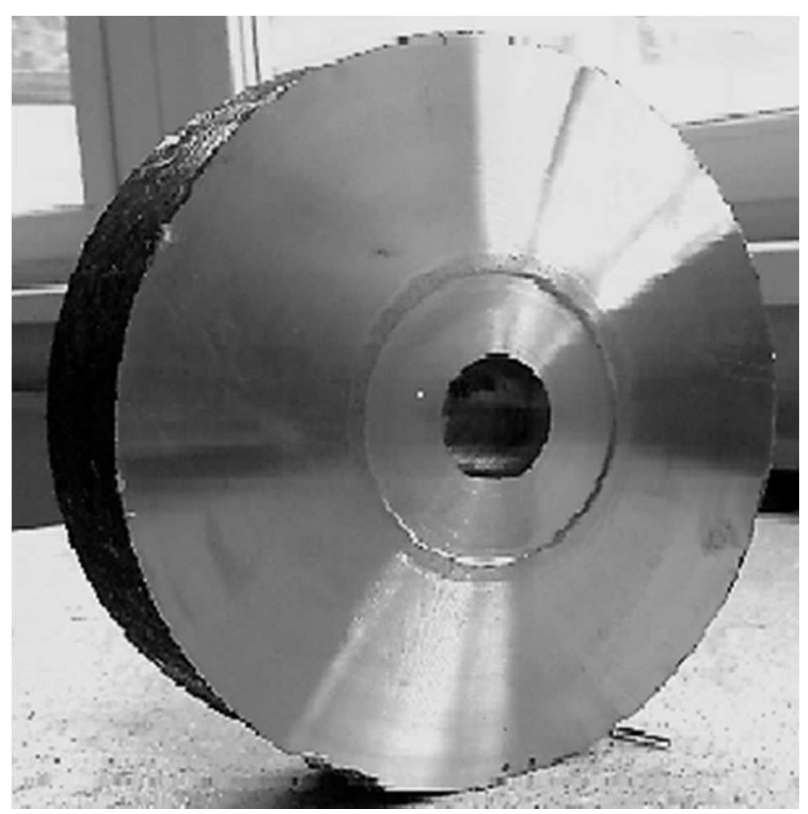

Fig. 2 Machined material - steel 12051.1

Due to the specifics of the experiments, as the turning holder was selected the type S25R - CSKPR 12 from Narex company (Figure 3) [18], which is commonly used for the turning of holes. It is profitable from the view of contact prevention between the back surface of cutting plate and machined surface when the tool is working at the small diameter of workpiece. Hereby, the design of holder ensures the sufficient rigidity at adequately tool protrusion.

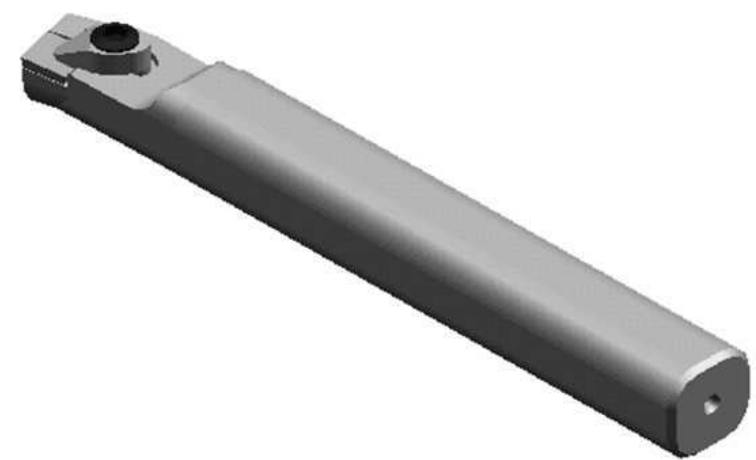

Fig. 3 Virtual model of turning holder Narex $S 25 R-$ CSKPR 12 [18]

In order to execute the sufficient number of measurements, totally 76 samples - cutting tips (three types of material, minimum twenty of every type) were prepared for tests. The samples type PM (labeled in Table 1) have been produced from high speed steel Vanadis 30 (SN 41 9830) of German company UDDEHOLM by means of powder metallurgy (PM). Tool faces of one group of these tips were processed by nitridation - they are samples type $P$ (VA30 + nitridation). The second group of samples - type $\mathrm{F}$ - have been produced from the Vanadis 30 that was alloyed by $\mathrm{Nb}$ (they were without nitridation).

A tool life of cutting tips made from the material listed above was compared with a durability of high speed steel Radeco (SN 41 9830) produced via casting metallurgy. This type of samples was labelled by letter " $R$ ".

The chemical composition of high speed steels produced on the base of powder and casting metallurgy with their identification are shown in Table 1.

Tab. 1 Chemical composition of investigated high speed steels

\begin{tabular}{|c|l|c|c|c|c|c|c|c|}
\hline Label & High Speed Steel & Produced via & C [\%] & W [\%] & Cr [\%] & V [\%] & Mo [\%] & Nb [\%] \\
\hline P & PM VA30 + nitridation & powder metallurgy & 0.9 & 6.0 & 4.3 & 1.9 & 5.0 & - \\
\hline F & PM VA30 + Nb [8] & powder metallurgy & 1.3 & 6.5 & 4.3 & 1.9 & 5.0 & 1.9 \\
\hline R & Radeco (SN 41 9830) & casting metallurgy & 0.90 & 6.4 & 4.10 & 1.8 & 5.0 & - \\
\hline
\end{tabular}

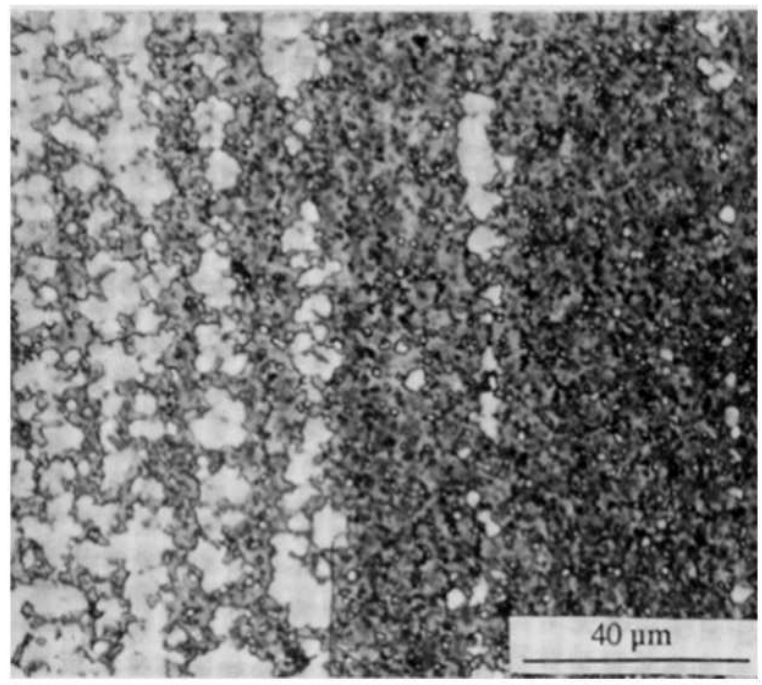

a) casting metallurgy

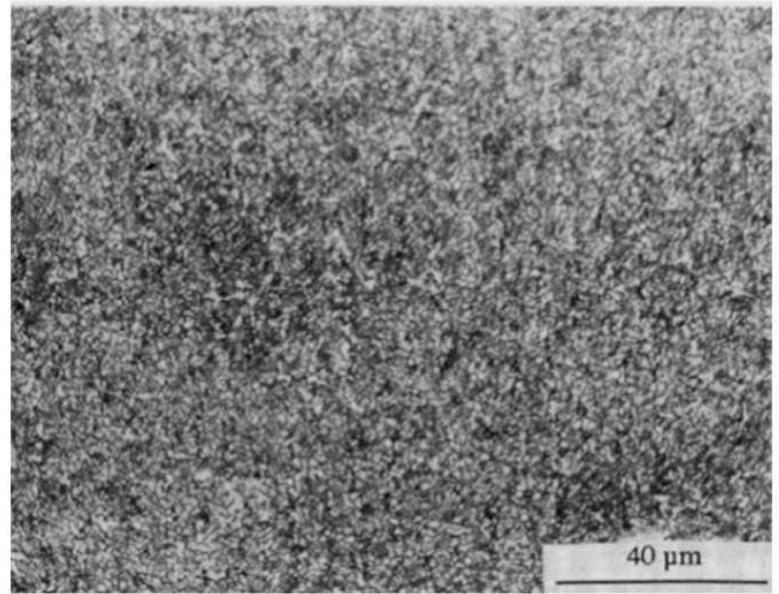

b) powder metallurgy

Fig. 4 The microstructures of steel SN 419830 according to its production 
The microstructures of steel SN 419830 for both approaches to its production (via powder and casting metallurgy) are shown in Figure 4. It is evident from these microstructures that the steel produced via powder metallurgy method has a more homogeneous and isotropic structure, as it was predicted with a respect to the reference [14].

The shape of all cutting tips was the type SPUN 120504 , it was selected according to the standard ISO. This design is suitable in terms of very good technological possibility for production as well as in terms of cutting material saving - one cutting tip has 4 cutting edges and raw product is easily prepared in normal sections. The geometrical parameters of cutting tip in the tool-in-hand system were given with regard of selected machined material 12050.1 as follows:

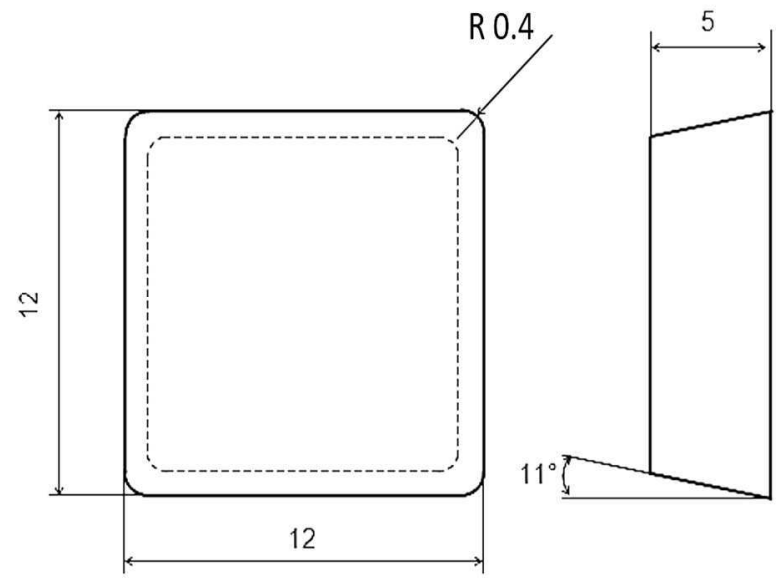

$$
\begin{aligned}
& \text { - tool orthogonal clearance } \alpha_{\mathrm{o}}=11^{\circ} \\
& \text { - tool orthogonal rake } \gamma_{\mathrm{o}}=0^{\circ} \\
& \text { - corner round radiusr } r_{\varepsilon}=0.4 \mathrm{~mm} \\
& \text { - tool major cutting edge angle } \kappa_{\mathrm{r}}=75^{\circ} \\
& \text { - tool minor cutting edge angle } \kappa_{\mathrm{r}}^{\prime}=25^{\circ} \\
& \text { - tool major cutting edge inclination } \lambda_{\mathrm{s}}=6^{\circ} \\
& \text { - tool minor cutting edge inclination } \lambda_{\mathrm{s}}^{\prime}=0.5^{\circ}
\end{aligned}
$$

The geometry of cutting tip, type SPUN 120504 according to standard ISO, is presented in Fig. 5, where also an example of real cutting used at the experimental investigation is shown.

Fig. 5 Basic geometrical characteristics of the cutting tip and an example of real cutting tip

With respect to the test methodology and with respect to the possibilities provided by a set of a machine - tool workpiece - fixture (especially an interaction between tool - workpiece), the following cutting parameters were selected for experiments:

- $\quad$ cutting depth $1 \mathrm{~mm}$;

- $\quad$ feed per revolution $0.2 \mathrm{~mm}$;

- the spindle speeds have been selected with a factor 1.6. With regard to the criterion of cutting edge wear (EA) in one contact, the spindle speeds were set in the range of $180-355 \mathrm{~min}^{-1}$.

Experiments were carried out without coolant. The criteria of the wear of cutting edge for these tests were stated by reducing the depth of cut by more than $20 \%$ or a complete loss of cutting ability called EA (Anihilation Edge). [19]

\section{Results of experiments}

The requirements of the durability testing methodology were met in all experiments. During the experiments performing, it was taken a care to achieve high rigidity of the set, constant depth of cut and eliminating the effects of vibration at high cutting speeds. During machining, the chips were regularly removed from the cutting area to prevent destruction of the cutting tip due to wedging of chips between the tool tip and the workpiece. The shape of the chips varied from a crumbly, through screwy, up to a ribbon shape. Measured values of diameter $\varnothing D_{n}$, at which a critical wear has been achieved, obtained for cutting tips type $\mathrm{F}(\mathrm{PM}$ VA30 $+\mathrm{Nb})$ are shown in Table 2.

The measured values were submitted to the remoteness testing according to Grubbs' test at the significance level of 0,05 that indicates a $5 \%$ risk of concluding that a difference exists when there is no actual difference. [9] The results of statistical processing confirmed the strong functional dependences of the measured values in all studied cases.

The graphical interpretation of the cutting tool durability is in this study represented by dependencies of achieved critical radius and cutting speed on spindle speed, which are shown in Figures 5 and 6.

It follows from the comparison of the measured values at spindle speed $224 \mathrm{~min}^{-1}$ that the material type F (PM $\mathrm{VA} 30+\mathrm{Nb}$ ) shows $20 \%$ higher durability than R (Radeco) and $8 \%$ than P (PM VA30 + nitridation).

After achieving a critical wear, it comes to the destruction of cutting tips. The shapes of cutting tips types $\mathrm{F}$ and $\mathrm{R}$ before the cutting and after the wear (after the total loss of the possibility to cut) are shown in the Figure 7. 
Tab. 2 Measured values of critical diameter

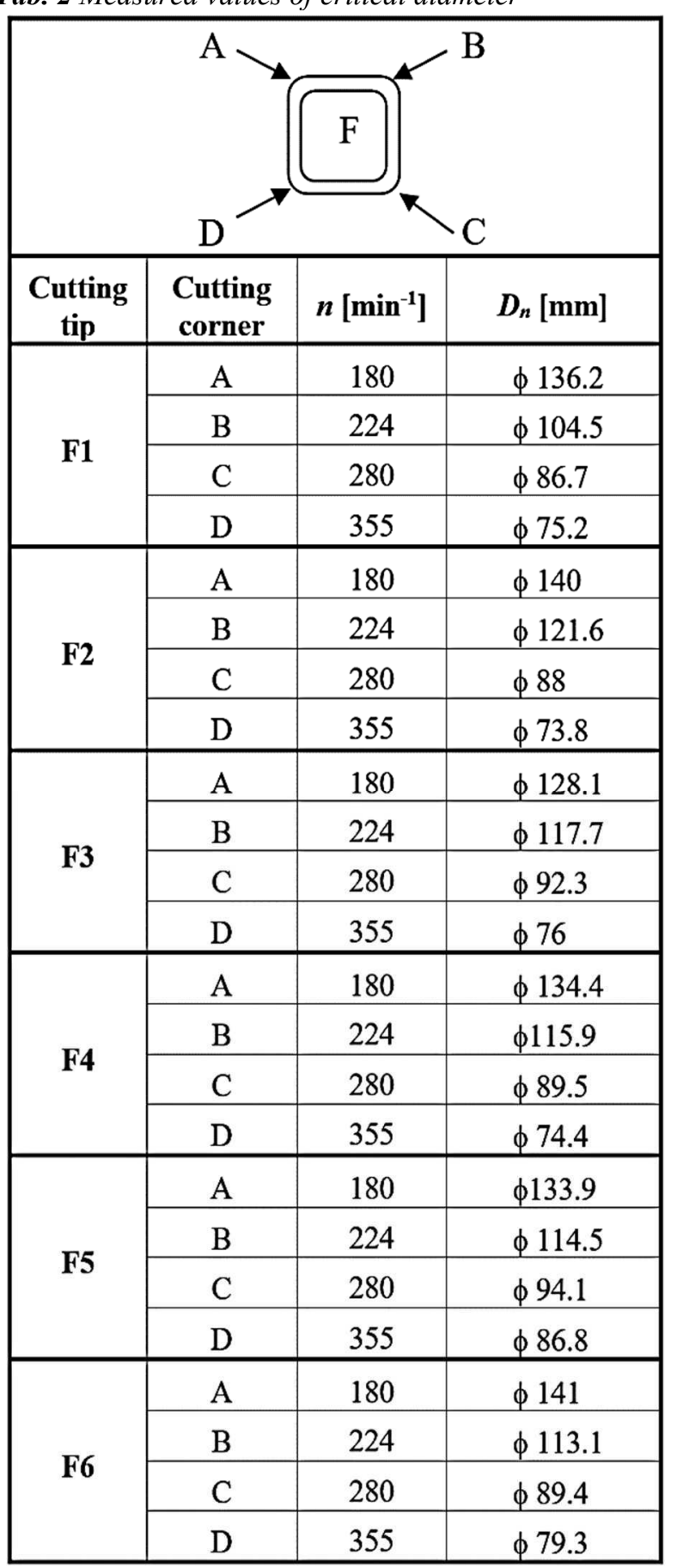

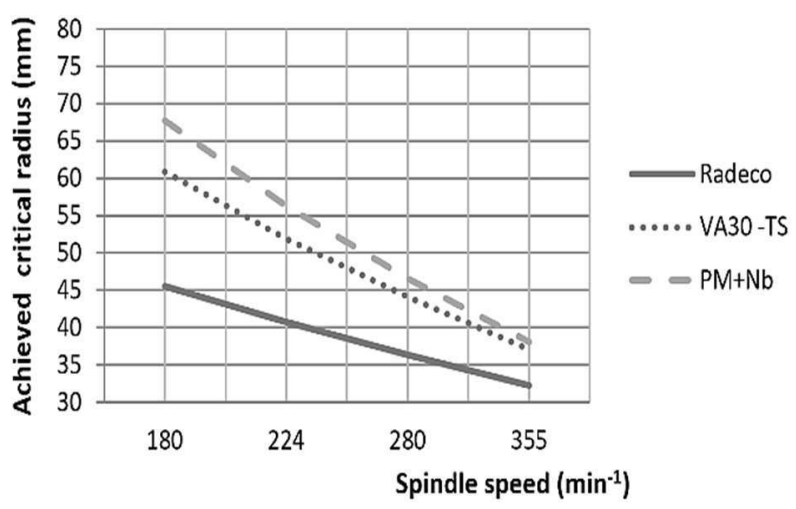

Fig. 5 Dependency of critical radius on spindle speed

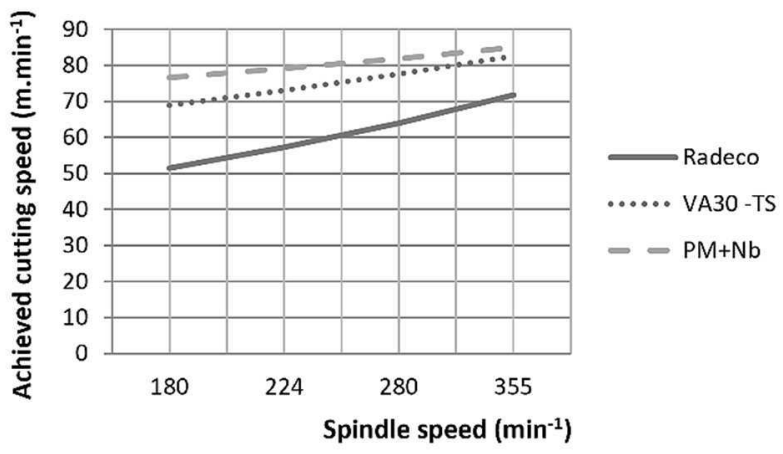

Fig. 6 Dependency of cutting speed on spindle speed

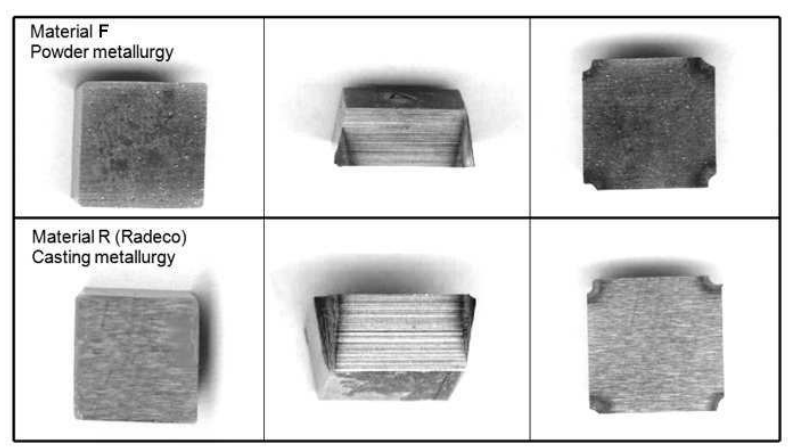

Fig. 7 The shape of two cutting tips before machining and after their wear

\section{Summary}

Despite the fact that at the moment there are a considerable number of cutting materials, the cutting life of which exceeds the lifetime of high-speed steels several times, they are nevertheless indispensable for the production of tools. Therefore, the interest in high-speed steels produced via powder metallurgy increases. This technology becomes attractive also from an environmental point of view, since it is convenient for non-waste technology.

The results have shown that the most appropriate material for production of cutting tips from the studied three HSS (ranked based on durability point of view) appears Vanadis 30 produced via powder metallurgy alloyed by $\mathrm{Nb}$. The worst durability has been achieved by high speed steel Radeco produced via casting metallurgy.

It can also be said that a better impact on the durability of a cutting tip tool made from HSS Vanadis 30 via powder metallurgy has alloying by $\mathrm{Nb}$ compared to the face surface nitriding.

Based on the results, it can be said that cutting wedges made from HSS via powder metallurgy keep their shapes and dimensions up to the loss of cutting ability, which was set as a criterion for the wear. The using of HSS produced via powder metallurgy is more technological and economical efficient than the using of HSS produced through casting metallurgy at stated criteria of the wear and given cutting conditions.

The obtained know-how related to the high-speed steel durability will enable to the producers to make a good decision about what type of tool material should be used at the machining in specific conditions in order to achieve good quality of machined surface while achieving the required level of energy consumption. 


\section{Acknowledgement}

The present contribution has been prepared with direct support of Ministry of Education, Science, Research and Sport of Slovak Republic through the projects KEGA 007TUKE-4/2018 and VEGA 1/0795/19.

\section{References}

[1] ZHONG, H. et al. (2010) Development of powder metallurgy high speed steel, Materials Science Forum, Trans Tech Publications. Switzerland, Vols. 638-642, pp. 1854-1859.

[2] MESQuitA, R. A., BARBOSA, C. A. (2009) HSS Produced Through Conventional Casting, Spray Forming and Powder Metallurgy, Brazil, 6th International tooling conference, pp. 387-402.

[3] RODZINAK D., HVIZDOS, P. et al. (2010) The effect of pin hardness on wear of sintered materials, In: Manufacturing Engineering, Vol. 9(3), pp. 36-39.

[4] Patent n. 281966 (2001), conferrable 13.6. 2001, author: M. Miskovicova et al., owner: Institute of Material Research, Slovak Academy of Science Kosice.

[5] HANZL, P., ZETKOVA, I., MACH, J. (2017) Optimization of the Pressure Porous Sample and Its Manufacturability by Selective Laser Melting, Manufacturing Technology, Vol. 17(1), pp. $34-$ 38 .

[6] MATESA, B., KOZAK, D., STOIĆ, A., SAMARDŽIĆ I. (2011) The influence of heat treatment by annealing on clad plates residual stresses, Metalurgija, Vol. 50(4), pp. 227-230.

[7] KROLCZYK, G. et al. (2015) Investigation of selected surface integrity features of duplex stainless steel (DSS) after turning, Metalurgija, Vol. 54(1), pp. 91-94.

[8] TEMUCIN, T. et al. (2013) A fuzzy based decision support model for non-traditional machining process selection, Technical Gazette, Vol. 20(5), pp. 787-793.
[9] VYCHYTIL, J., HOLECEK, M, (2010) The simple model of cell prestress maintained by cell incompressibility, Mathematics and computers in simulation, 80(6), 1337-1344.

[10] BURECEK, A., HRUZIK, L. VASINA, M. (2017) Dynamics of Linear Hydraulic Cylinder with Mass Load, Manufacturing Technology, Vol. 17(3), pp. 296-302.

[11] PETRU, J. et al. (2013) Influence of cutting parameters on heat-affected zone after laser cutting, Tehnicki Vjesnik, Vol. 20(2), pp. 225-230.

[12] MONKA, P. (2016) Design and experimental study of turning tools with linear cutting edges and comparison to commercial tools, Int J Adv Manuf Technology, 85, pp. 2325-2343.

[13] JURKO, J. (2011) Verification of cutting zone machinability during the turning of a new austenitic stainless steel, Adv. Comp. Sci. Edu. Appl., 202(2), pp. 338-345.

[14] MALOTOVA, S. (2016). Roughness Evaluation of the Machined Surface at Interrupted Cutting Process, Manufacturing Technology, Vol. 16(1), pp. 168-173.

[15] ZETEK, M., ZETKOVA, I. (2017) Influence of the Workpice Quality on the Cutting Tool Life when Gear Wheel are Machined, Manufacturing Technology, Vol. 17(1), pp.121-125.

[16] CEP, R. et al. (2014) Surface roughness after machining and influence of feed rate on process, Key Engineering Materials, Vol. 581, pp. 341-347.

[17] KADAROVA, J., MIHOK, J. et al. (2013) Proposal of performance assessment by integration of two management tools, In: Quality Innovation Prosperity 17(1), pp. 88-103.

[18] CIZMAR, J.: Diploma thesis, FMT TU Kosice with seat in Presov (2002).

[19] UNGUREANU, M. et al. (2015) Product Innovation Management for Business Development, Proceedings 5th Central European Conference in Regional Science (CERS), pp. 1112 - 1118. 